\title{
ENSURING SUSTAINABLE AND RESILIENT AIR TRAFFIC MANAGEMENT SYSTEMS FOR SOUTH AFRICA WITH COMPLEXITY AND WHOLE-OF-SOCIETY THEORY APPROACHES
}

\author{
L.V. Weiland ${ }^{1,2 *}$, C. Law ${ }^{1} \&$ B.P. Sunjka ${ }^{1}$
}

\section{ARTICLE INFO}

\section{Article details}

Presented at the $31^{\text {st }}$ annual conference of the Southern African Institute for Industrial Engineering (SAllE), held virtually from 5-7 October 2020 .

Available online $\quad 11$ Nov 2020

\section{Contact details}

* Corresponding author Weila8f3@erau.edu

Author affiliations

1 School of Mechanical, Industrial and Aeronautical Engineering, University of the Witwatersrand, Johannesburg, South Africa.

2 Embry-Riddle Aeronautical University, College of Aeronautics, Daytona Beach, Florida, USA

\section{ORCID ${ }^{\circledR}$ identifiers}

L.V. Weiland

https://orcid.org/0000-0002-6481-6952

C. Law

https://orcid.org/0000-0002-0292-8115

B.P. Sunjka

https://orcid.org/0000-0002-6605-6344

\section{DOI}

http://dx.doi.org/10.7166/31-3-2424

\section{ABSTRACT}

Air traffic management is a complex multi-disciplinary socio-technical system of systems that directly supports the air transportation industry. With the introduction of new technologies into the air traffic management system, there is a lack of understanding of the effects of new technology on people, machines, procedures, and regulatory environments. There is thus a demonstrable need for methods to determine credible requirements that can be used to outline operating procedures, policies, tools, and techniques for continued resilience. The purpose of this paper is to develop a conceptual framework using the 'whole-of-society' perspective and tools such as complexity theory, applying these to air traffic management in South Africa. The framework is developed further to understand the requirements for ensuring a resilient and sustained air traffic management network

\section{OPSOMMING}

Die bestuur van lugverkeer is 'n ingewikkelde, multidissiplinêre, sosiotegnologiese stelsel van stelsels wat die lugvervoer industrie ondersteun. Die bekendstelling van nuwe tegnologieë aan die lugverkeer bestuurstelsel het gelei tot 'n gebrek aan begrip van die invloed van nuwe tegnologie op mense, masjinerie, prosedures en regulerende omgewings. Daar is dus 'n behoefte aan metodes om geloofwaardige vereistes te bepaal wat gebruik kan word om bedryfspraktyke, beleide, gereedskapstukke en tegnieke te verbeter met die oog op voortgesette aanpasbaarheid. Die doel van hierdie artikel is om 'n konseptuele raamwerk te ontwikkel wat gebruik maak van die 'hele samelewing' perspektief en tegnieke, soos kompleksiteitsteorie, en om dit op Suid-Afrikaanse lugverkeer bestuur toe te pas. Die raamwerk is verder ontwikkel om die vereistes van 'n volhoubare en aanpasbare lugverkeer bestuurstelsel te verstaan.

\section{INTRODUCTION}

This paper proposes a conceptual framework that can be used to examine air traffic management (ATM) communication resilience and sustainability in South Africa. The objective is to develop a framework that can be used to examine air traffic services provided by Air Traffic Navigation Services (ATNS) as the air navigation service provider (ANSP) for South Africa. The framework uses complexity theory as its foundation to combine safety management systems, and software, hardware, environment, liveware-liveware (SHELL) with the whole-of-society and resilience analysis grid (RAG) models. The SHELL model is explained in detail in the Literature Review section that includes explanations of all the models used in this research. It gives a detailed explanation of the liveware to liveware interaction. Framework could also be used in other air navigation service providers' locations for the same reasons, and would help to bring about global harmonisation in sustainability and resilience for air traffic systems. This framework goes beyond the current processes in ATM that favour safety and human factors with the safety management system (SMS) SHELL and collaborative decision methods (CDM) models $[1,2,3]$. However, technological advances are being employed in air traffic management that require more complex analysis for sustainability. 
ATM is a system of systems that can also be described as part of a complex social-technical system [4] that directly supports the air transportation industry by delivering a safe and effective service [4]. ATNS provides ATM in South Africa, and is responsible for providing and maintaining resilient and sustainable ATM [5]. Airspace safety performance is a fundamental aspect of their business. In anticipation of increased air traffic movements and continuous improvement in systems, they have three main components to the organisation: communication, navigation, and surveillance, known as the CNS infrastructure; supplementary aviation services; and ATM [5]. ATNS delivers air traffic services to about one-tenth of the global airspace [5], and is an ideal location for studying resilience and sustainability in ATM. Figures 1 and 2 show the complex social-technical operation and ATNS presence in South Africa. Figure 1 shows an overview of ATNS, highlighting the complexity through phases of flight, types of airspace, types of interfaces of equipment, and the CNS infrastructure. Figure 2 shows ATNS facilities throughout South Africa. Safety and security are not always looked at in the same way in air traffic control. However, with continued development in the industry's infrastructure, there is a tendency to favour one over the other [3]. They often overlap and are involved with each other; so the integration of both safety and security analysis is needed, because air traffic movement is part of all countries' critical infrastructure [5].

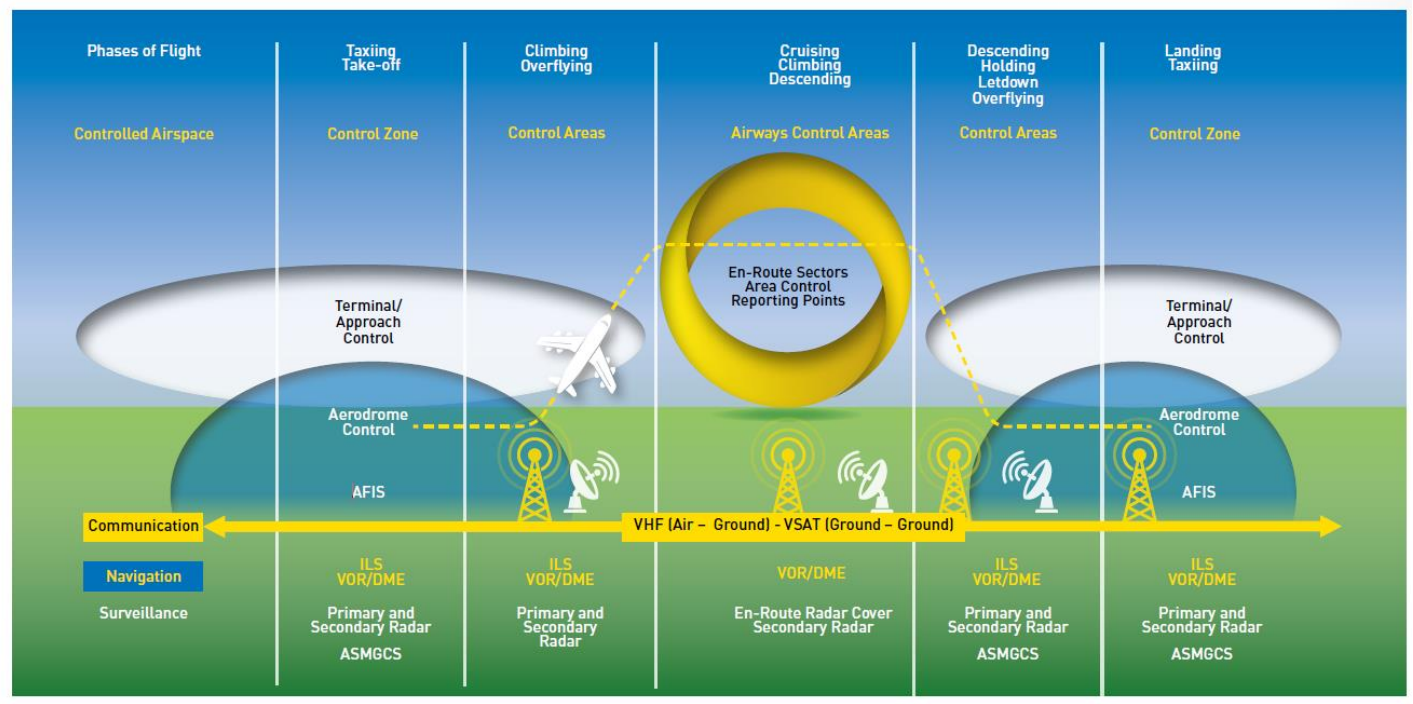

Figure 1: ATNS service overview [5]

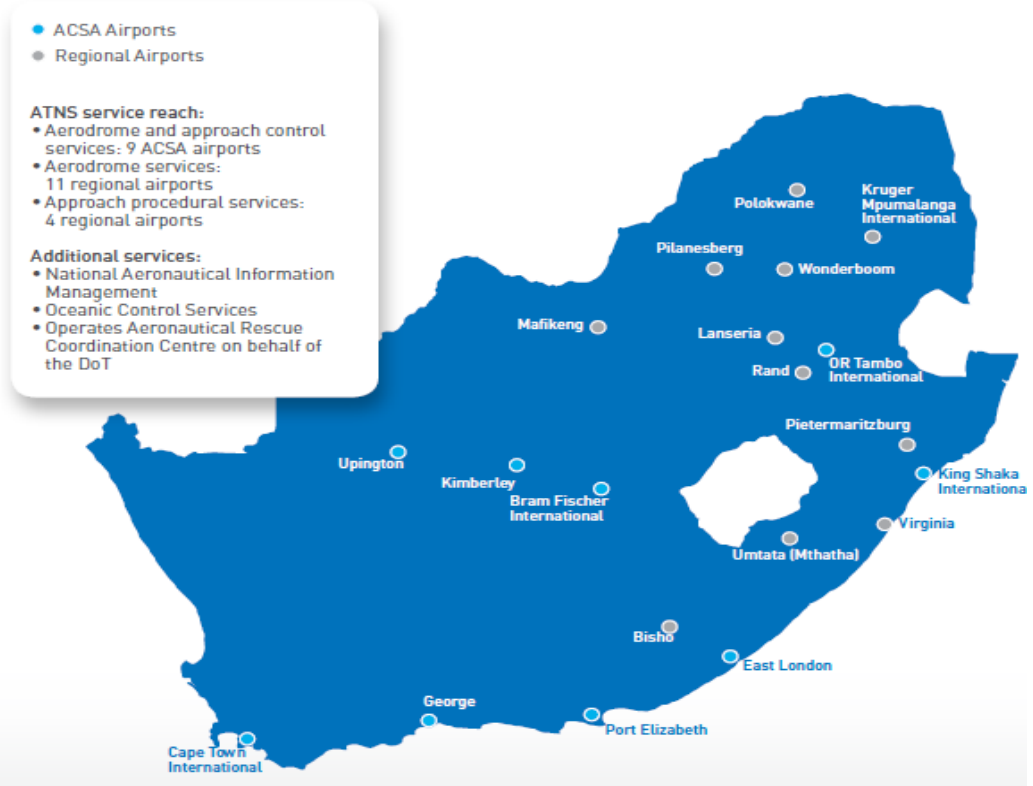

Figure 2: ATNS presence in South Africa [5] 
The safety ratio that ATNS uses is per 100,000 movements [5]. In the past, many of the incidents and accidents, risks, and resilience issues were identified using safety approaches in SMS through resilience engineering (RE) [8]. One of the primary models used relates to human factors, and employs the SHELL model. Commercial aviation and ATM have been considered very safe, as the risk of a mishap has been classified below one accident per one million operations [5].

ATNS have allocated a significant amount of capital expenditure to ensure the sustainability of communication, navigation, and surveillance technology positioned for air traffic movement [5]. They also work in conjunction with the Council for Scientific and Industrial Research (CSIR) to increase operational efficiency [5]. As global ATM organisations work to maintain a sustainable and resilient system, they need to ensure a clear understanding of the effects of new technology, which impacts people, machines, procedures, and items from the regulatory environment. Because of the complexity of the situation, there is a need for tools or techniques that consider operating procedures, policies, and technology for continued resilience - or, better stated, they need to ensure that all stakeholders are involved.

Baxter and Sommerville [6] describe a social-technical system (STS) as one that requires hardware, software, personal, and community characteristics that are able to find cost-effective ways to incorporate new technologies in a resilient and sustainable manner. This is significant because it indicates more tolerable systems to clients and delivers better value to participants. Social-technical systems engineering (STSE) may also link between organisational transformation and system improvement [6]. This STS has relied on the safety management system's SHELL model in the past for resilience and sustainability. This evidence is shown by the fact that SHELL concepts have played a significant role for many years in air traffic control by locating and following aircraft from ground-based radar analogue systems to the current upgraded locating and following with the use of satellites through standard terminal automation replacement systems (STARS), where digitised automation surrounds the controllers who control aircraft instead of ground-based equipment [9]. A drawback may be that this does not always account for security requirements by introducing new technologies [3]. The move from analogue to digital communications in airspace has brought in additional security considerations for air traffic management. These improvements have also brought software engineering approaches to the forefront, and increased the aviation community's challenges in ATM. This technology shift from traditional radar-based to systems of systems identified issues that need solutions for resilience. A study, revision, and re-defining of current policies, standards, and cultural norms is needed to alleviate the risks. Practical STSE brings connection between organizational transformation and system advancement with a set of interdisciplinary research problems that address how to apply social-technical approaches. These approaches need to be cost-effective, employing expeditious integration with the existing systems $[3,6]$.

Cook, et al. [11] introduced complexity science and its application in an ATM transport context, and presented a synopsis of complex network security theory with examples supported by metrics. They also made contributions to the theory with analysis through case studies [11]. Their objectives of introducing complexity theory aspects with illustrations from the air traffic context and metrics, focusing on the complexity of network systems [11], lends credence to the need for the further development of resilience understanding and applications. This also suggests a useful theoretical lens.

A conceptual framework that is supported by complexity science, through the integration of the disciplines from a SMS SHELL model and whole-of-society approach, needs development. This development would lead to tools and techniques that are validated through triangulation, employing the resilience analysis grid (RAG) [10] to show resilient performance. This development would take the current ATM system, based on safety management, to a higher functioning system that mitigates or possibly prevents adverse events [10].

This paper proposes a conceptual framework that can be used to examine ATM communication resilience and sustainability in South Africa. The objective is to develop a framework that can be used to examine air traffic services provided by ATNS as the ANSP for South Africa. However, technological advances are being employed in air traffic management that require more complex analysis for sustainability.

\section{RESEARCH METHOD}

This work will review the use of complexity theory, SHELL, whole-of-society, and RAG in current approaches. The discussion will include how these could be used as a framework, combining methodologies that include complexity. Using data from this critical literature review, a framework will be proposed that can be used for further research into developing a resilient system. 
An understanding and application of resilience is explored using complexity theory as its foundation. It then combines the SHELL model to data-mine information from regulations, policies, and procedures between the components. These components will be moved into the whole-of-society transformation through the involvement of all stakeholders. Finally, the research will discuss how this process can be validated through a RAG.

\section{LITERATURE REVIEW}

Various models have been used individually in a piecemeal analysis of ATM. Few have looked at the industry's entire representation, other than in a few documents that stress the need for collaboration [3, 12]. Complexity theory, SHELL, whole-of-society with a vertical application, and RAG are discussed in a way that shows current stand-alone use, coupled with a continuous process or flow from one area to the next. This is a new approach or combination approach that could be employed to ensure resilience and sustainability. Existing approaches are analysed for cause-and-effect and risk management. And concepts are brought in that have been enhanced and developed to identify vulnerabilities and mitigate risk for resilience and sustainability.

\subsection{Complexity theory}

Complexity science is the multi-disciplinary knowledge of complex systems [11]. It is in the foreground of more than one discipline, and is considered a driver of integration when many stakeholders are involved [12]. Goldreich [13] discusses complexity theory's concern with 'intrinsic complexity' and the importance of accommodating the relations between numerous computational phenomena - in other words, relating one fact about calculation difficulty to another fact. Complexity theory has not always been successful in finding absolute answers [13, 14]. By itself, it may not meet the standards of resilience and sustainability in the ATM arena; however, Ripley and Larkin have analysed its value as a conceptual lens for complex systems in aviation management [15]. Air transportation networks and integrated airspace are prime complexity examples of operation. Current research favours a comprehensive approach to safety and human factors [3, 9, 11]. Dekker, Cilliers, and Hofmeyr [16] explore the complementary use of science, using complexity for analysis in complex systems that might not clash with stakeholders. This should not be discounted, as security and technology issues are relatively new in ATM, and will still have the safety and human factor implications in all the services provided. Complexity has also been linked to sustainable theories as a foundation for combining diverse theoretical methods in sustainability [17]. One idea is to have a framework that represents modifications for sustainability. In this process, Figure 3 illustrates an example of how the adaptive cycle and complexity works across different sciences. This process should give the reader evidence of its application in the ATM business.

Complexity science is the integrated approach that is the foundation for combining SHELL and whole-ofsociety, and is validated with RAG applications. The combination could also help users better understand phenomena in air traffic's evolving behaviours, especially those with safety and security implications. It may likewise help to build a genuinely all-inclusive performance assessment framework that considers uncertainty in real-world complex systems, as required in an ATM environment. Cook et al. [11] have applied complexity science to ATM by introducing some key concepts, with a concentration on and a general attention to the air transportation industry, and specifically to air traffic control (ATC). Their concentration was on performance assessment and system design with effective service to passengers. They did this, keeping in mind the complexity of the air transport industry network systems and the integrated blocks of airspace [11]. This analysis of software, hardware, environment, liveware and liveware involvement also incorporates the concepts of safety management systems, in particular the SHELL notion. 


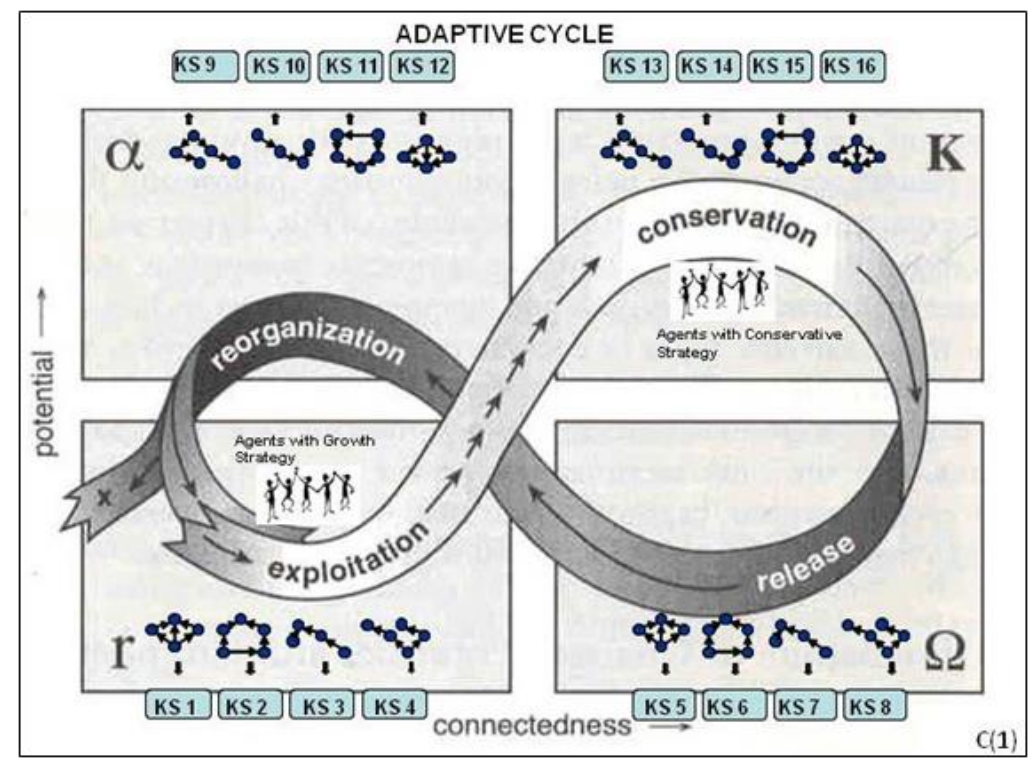

Figure 3: Adaptive cycle and complexity theory, adapted from Swilling and Peter [17]. KS 1 to KS 16 denote 'knowledge sets'.

\subsection{Software, hardware, environment, liveware-liveware (SHELL)}

The software, hardware, environment, liveware-liveware (SHELL) model defined in the International Civil Aviation Organization (ICAO) Document 9859 Safety Management Manual is a theoretical instrument used to evaluate the interface of multiple systems sections [19]. A software item would be ATM procedures and manuals. Hardware is the ATM equipment. An environment element would be the workspace conditions, and liveware-liveware would be the actors and their interactions [18, 19]. A critical focus of the model is the human on the front line, and understanding that the human is the least predictable and most susceptible to the effects of internal and external influences. The International Civil Aviation Organisation (ICAO) [19] states:

Liveware-Liveware ( $L-L)$. The $L-L$ interface is the relationship and interaction between people in the work environment. Some of these interactions are within the organization (colleagues, supervisors, managers). However, many are between individuals in different organizations with different roles (air traffic controllers with pilots, pilots with engineers, etc.). Therefore, it is important to recognize that communication and interpersonal skills and group dynamics play a role in determining human performance. The advent of crew resource management (CRM) and its extension to air traffic services (ATS) and maintenance operations has created a focus on team performance to manage errors. Also, within the scope of this interface are staff/management relationships and organizational culture (p. 32).

This is expanded on in an example of computer-human factors analysis/interaction for the standard terminal automation replacement system (STARS), which provides radar services to air traffic control from a terminal radar approach control (TRACON) station [9], as shown in Figure 4, which emphasises going from analogue Cathode-ray Tube (CRT) radars in using STARS. The most captivating part of the analysis is the relationship change, or how the controller interacts with other liveware in the L-L relationship. Figure 5 illustrates the liveware interaction between humans in a control tower at an airfield, and the importance of the SHELL concept in identifying livewire interactions. Using SHELL gives an initial assessment of the current situation in air traffic management for the ATM system of interest. It may also identify most, if not all, of the stakeholders. This is an initial step in assessing current resilience and sustainability in the environment. Miller et al. [9] discussed details of some of the current technologies employed in the industry, and how new automation and technology still needs analysis. Their research also assessed cognitive processing issues with technology, and was able to identify areas of concern for improvement. The authors were also able to apply the concept from radar to air traffic control tower team operations [20]. As stated in ICAO SMS, the liveware-liveware element is the most unpredictable because it is based on humans as they interact with software, hardware, and the environment. This makes it possible to use the SHELL with each instance of software, hardware, and environment. The STARS and the tower show only one type of software and hardware, so more research could be completed with each system in the ATC systems. 


\section{The SHELLModel 2017 and Computer/LHuman Factors Anallysis for STARS TRACON}

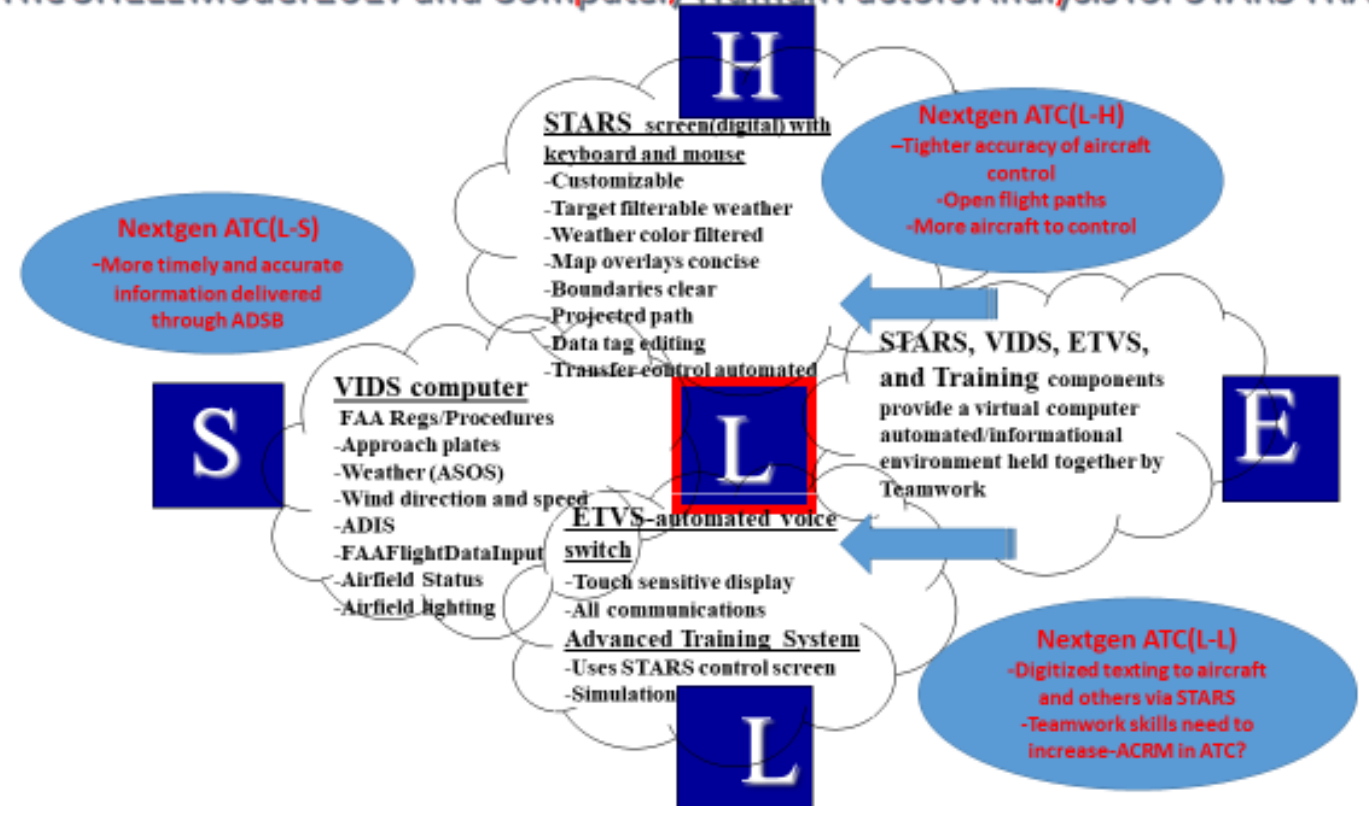

Figure 4: The SHELL model (2017), adopted for the computer/automation information of the STARS TRACON controller with predicted NextGen ATC effects by Miller et al. in 2019 [9].

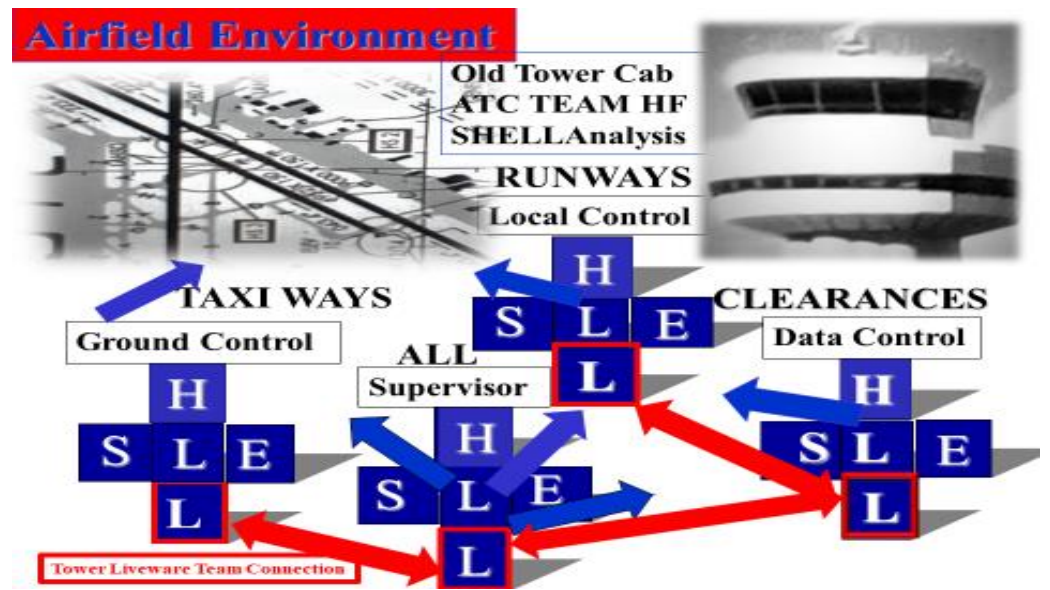

Figure 5: Tower control human factors (HF) SHELL analysis based on the model by Hawkins [21], modified to depict the liveware-liveware team interface [20].

\subsection{Whole-of-society}

Goncalves [12, 22] discusses whole-of-society applications in national difficulties such as security, and focused on poaching in South Africa. His research offers the possibility for use in ATM scenarios as the next step for resilience. Goncalves [12, 22] states that it should be used in situations that bridge multiple systems, and that need more than one integrating discipline. The argument is that complexity may require numerous interventions at numerous levels in the hierarchy. Goncalves's work showed how the integration could proceed through technology management that involves all stakeholders, who also have different observations and interests.

The current perception of security tasks, which needs to be brought into the consideration of complexity and safety, is analysis, prevention, response, and evaluation [23]. This goes further than some collaborative procedures in current use. For supportable resilience, air traffic needs to consider these tasks and ensure that they have identified all the stakeholders. Finding most of the stakeholders is done using the SHELL process. Other stakeholders may be identified through different processes; however, this is the start of a 
mutual understanding of a condition that could be used to develop risk mitigation applications and tools for resilience through better intervention. In the whole-of-society process, these would be applied in the transformation from security chain to intervention by identifying what tasks need to be completed, using what capabilities, and by whom, as discussed by Goncalves [12] in the transformation from security chain to the intervention phase as applicable to air traffic; this is illustrated in Figure 6. Thus all intervention blanks could be filled in with answers from ATM stakeholder involvement.

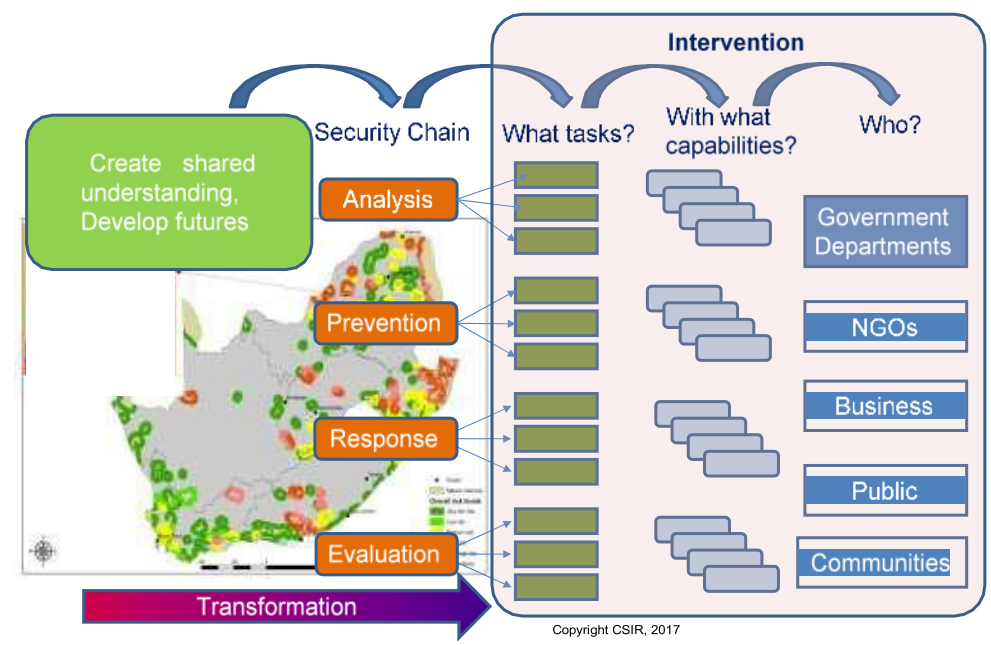

Figure 6: The whole-of-society approach [12]

The whole-of-society, as illustrated in Figure 6, builds on intervention through a shared understanding of the condition, so a shared method is used to find the solution. It goes beyond compliance to include integration because of the complexity. Goncalves [12] and Nicolescu [24] refer to these as 'reality levels', and identify four. Whole-of-society takes this further because of a variety of sustainability principles; it works across the organisation and removes individual departmental limitations [12]; and it brings in education to address solutions for the whole-of-society. There also need to be more interests or objectives, and this may be addressed with this process. In dealing with the complexity of wildlife crime [12], it proposes a vertically and horizontally integrated approach, as shown in Figure 7.

Figure 7 is not complete, but it points to a process that could be translated from a poaching scenario to an air traffic environment with minimal modification. It is believed that these lines for integrating the disciplines need a context level to understand that the situation includes regional, national, and global contexts. ATM may be divided by country or by ANSP, but this still has implications for a global environment. The second level could bring in solutions, and the third level would consist of capabilities. The final or fourth level brings in the deployment of current and new technologies. The four disciplines in the different levels of Figure 7 [12] can be applied to any complex system, including ATM. Further research analysis would need to complete the vertical and horizontal application or integration to ensure that all stakeholders are represented. By doing this first, further data gathering and analysis could be done to develop solutions for resilience. These solutions could be tested employing the RAG, which would lend itself to the proper tools and techniques for continued resilience. This additional data-gathering and analysis takes knowledge further than the current state of collaboration and cooperation, and considers enterprise engineering or the systems of systems in air traffic control. 


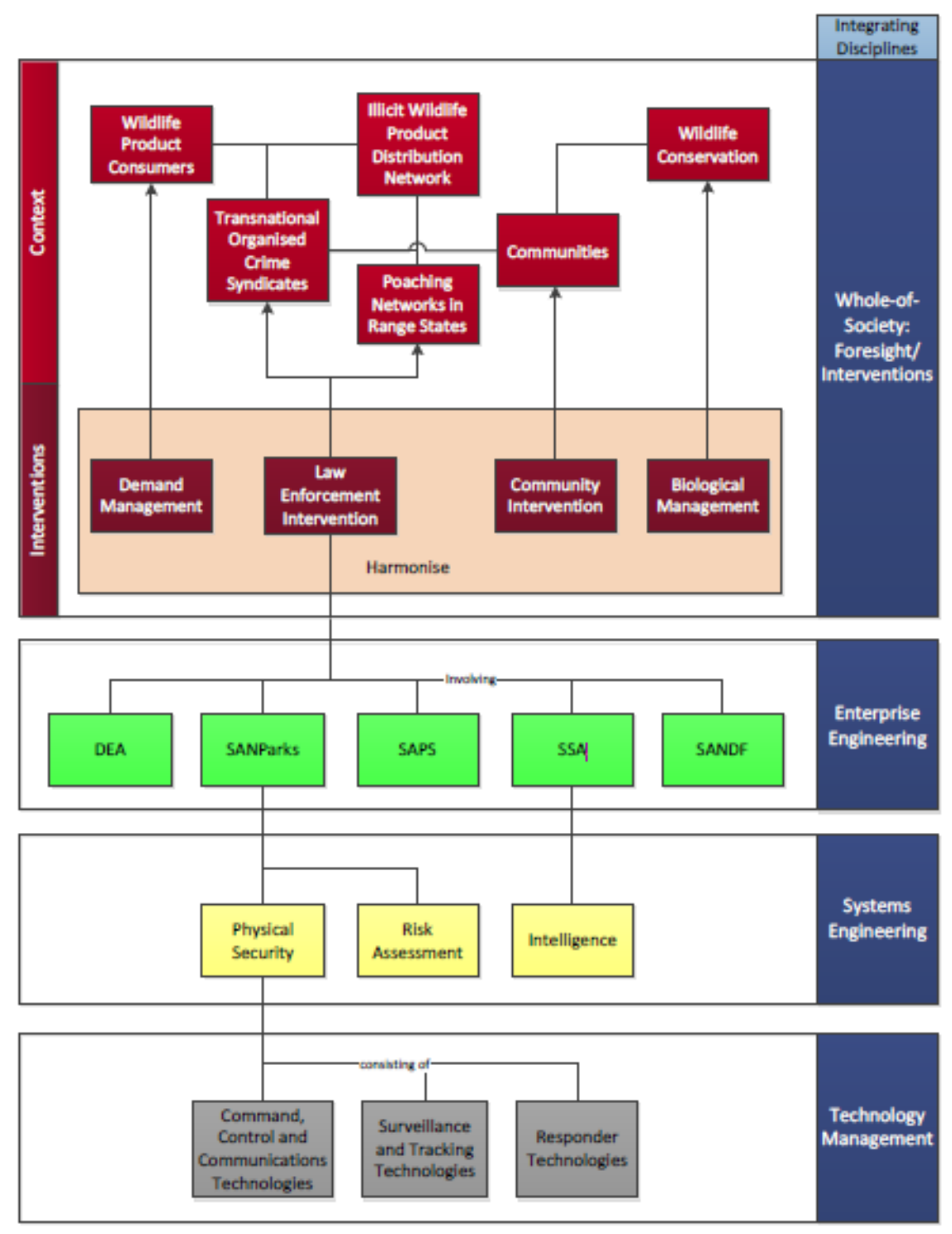

Figure 7. Vertically and horizontally integrated approach to addressing wildlife crime (incomplete model) [12]

\subsection{Resilience analysis grid}

The RAG is a process or a step of validation that may be employed after ensuring that all stakeholders are involved and that solutions have been identified from the whole-of-society phase [10] that go beyond the current process of collaborative decision-making (CDM). Currently, the ICAO and other organisations are proactive in collaborative decision-making. As outlined in this paper, CDM may not be enough. The ICAO [25] defines ATM and the ATM system as follows:

The dynamic, integrated management of air traffic and airspace including air traffic services, airspace management, and air traffic flow management -safely, economically and efficiently - through the provision of facilities and seamless services in collaboration with all parties and involving airborne and ground-based functions.

A system that provides ATM through the collaborative integration of humans, information, technology, facilities and services, supported by air and ground-and/or space-based communications, navigation, and surveillance. (pp.1-4) 
As the use of technology increases, there is a tendency to embrace a collaboration concept and believe that everyone will share information, collaborate, and integrate data with authorised users in a synchronised way [3, 12, 23, and 24]. However, as stated above, the industry is finding that this might not be the best way to ensure that a system is resilient, owing to the inherent complexity of advanced technologies. So once a whole-of-society approach has considered the transformation and intervention vertically and horizontally, it should be validated. This paper proposes that the validation be done using the RAG approach.

Resilience engineering is a concept from safety management, concentrating on complexity in systems to achieve success [10], [26]. At the same time, one must acknowledge that, while a system may not be resilient, it has the potential for resilient performance. Researchers believe that resilience has four foundations or abilities: responding, monitoring, learning, and anticipating [10] [26], as shown in its simplest form in Figure 8.

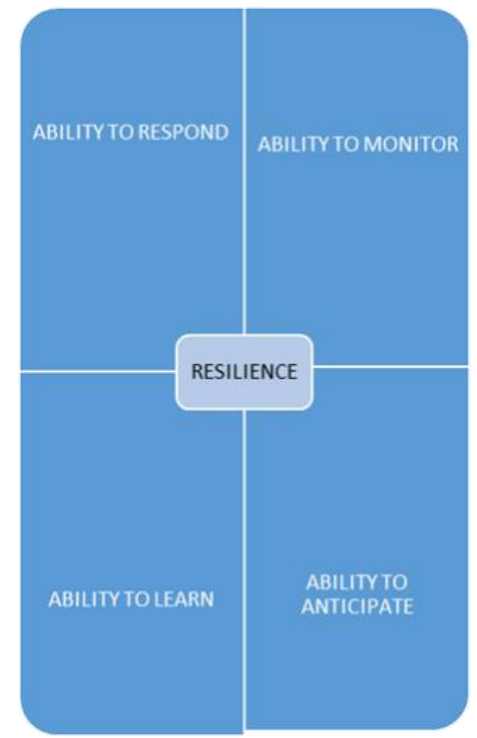

\section{Figure 8. Resilience analysis grid (RAG)}

Hollnagel [10] notes that, although safety is a quality, there is more to it than decreasing the number of adverse events. A key feature of a resilient system [10,26,27] is the ability to adjust because it uses the four foundations. Another benefit is that the resilience grid has the ability to work well with regulations in an industry, and it is basic, flexible, and uses graphs that are easy to understand [27]. These proactive and reactive adjustments are imperative in a dynamic air traffic management organisation.

There are many contradictory ideas in the literature on what is resilience engineering, or the 'phenomenology of resilience', or 'resilient performance'; so it might be better to focus on what supports resilience [10]. This is possible with validation after assessment, followed with the involvement of all stakeholders, for intervention and improvement. The literature shows that RAG has helped to assess organisational resilience in complex socio-technical systems where the resilience analysis grid has been combined with the analytic hierarchy process [26]. An analytic framework to assess organisational resilience concluded that resilience analysis grids, with a considered set of investigative questions, could be used in other fields as a support tool [26]. Thus, as whole-of-society falls into the category of 'analytic hierarchy process' [12] - with a grid of a weighed set of probing questions derived after assessment and transformation - it could validate resilience and sustainability. A metric and framework for the resilience analysis of engineered and infrastructure systems addresses the variety of practices that could build a framework that includes unbiased resilience background, susceptibility analysis, and stakeholder commitment. It extends the investigation into the unknown in resilient assessment while still keeping the use of likelihood [8]. A study [27] using the RAG was proposed to confront the lack of resilience metrics in a water system. Here again, the RAG [27] technique proved to be simple and flexible to use, and delivered pure and graphical results [27]. Knowing that the RAG process is flexible and is used in different industries makes it a viable validation tool for ensuring resilient ATM systems. 
A framework theory that can be completed and revised in both short- and long-term resilience and sustainability applications for ATM and control is presented here. Its most straightforward form is shown in Figure 9. Figure 10 shows the overlap that is involved between the sciences and the theories. Figure 11 shows the conceptual framework flow from the SHELL model to the sustainable tools and techniques.

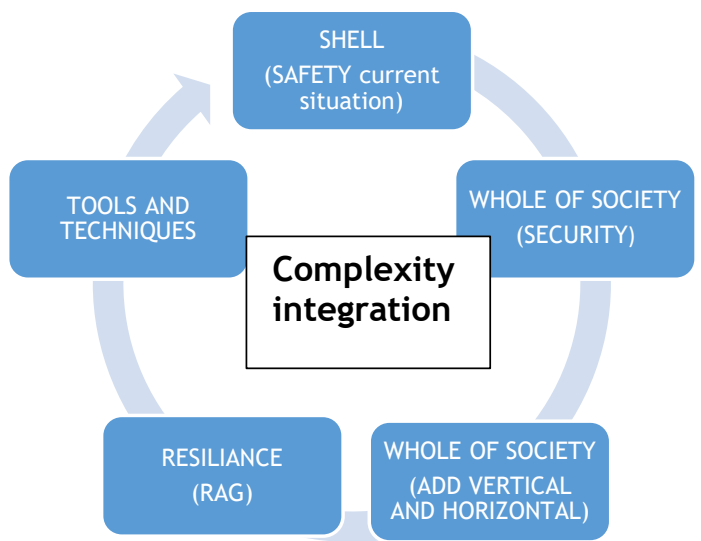

Figure 9: Conceptual framework for resilient sustainable ATM

Figure 9 illustrates the conceptual framework as a life cycle that is complex, because sustainability and resilience should be continuous for maximum benefit. The first step is to assess the ATM's current situation through the safety SMS SHELL model application. The second step is to move the results from the SHELL analysis into the whole-of-society security model application. The third step in the life cycle application is to implement the whole-of-society's vertical and horizontal application for added value. This will lead to the fourth step, which is to test through RAGs, thus identifying tools and techniques for continuous resilience and sustainability, and finally returning to assessment.

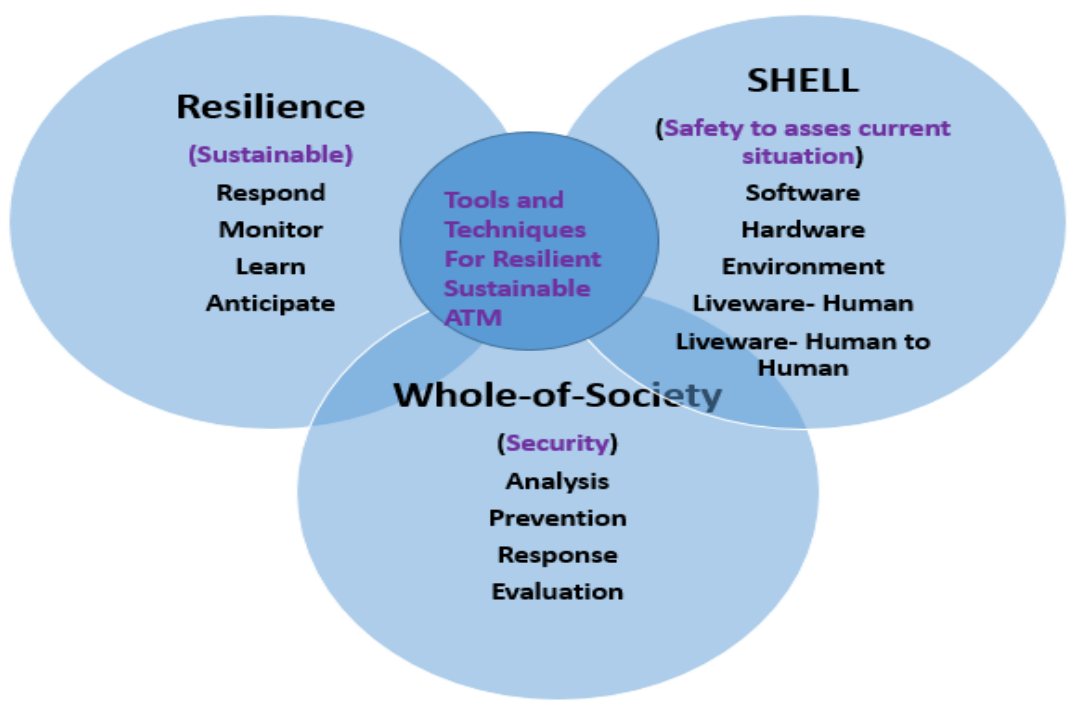

Figure 10: Complexity of sustainable and resilient ATM

Figure 10 shows more of the elements that are in the ATM application of the SHELL, whole-of-society, and resilience framework as applied in this research. It illustrates the overlap between the models and the complexity, thus showing how they are more valuable in identifying tools and techniques when done together. 


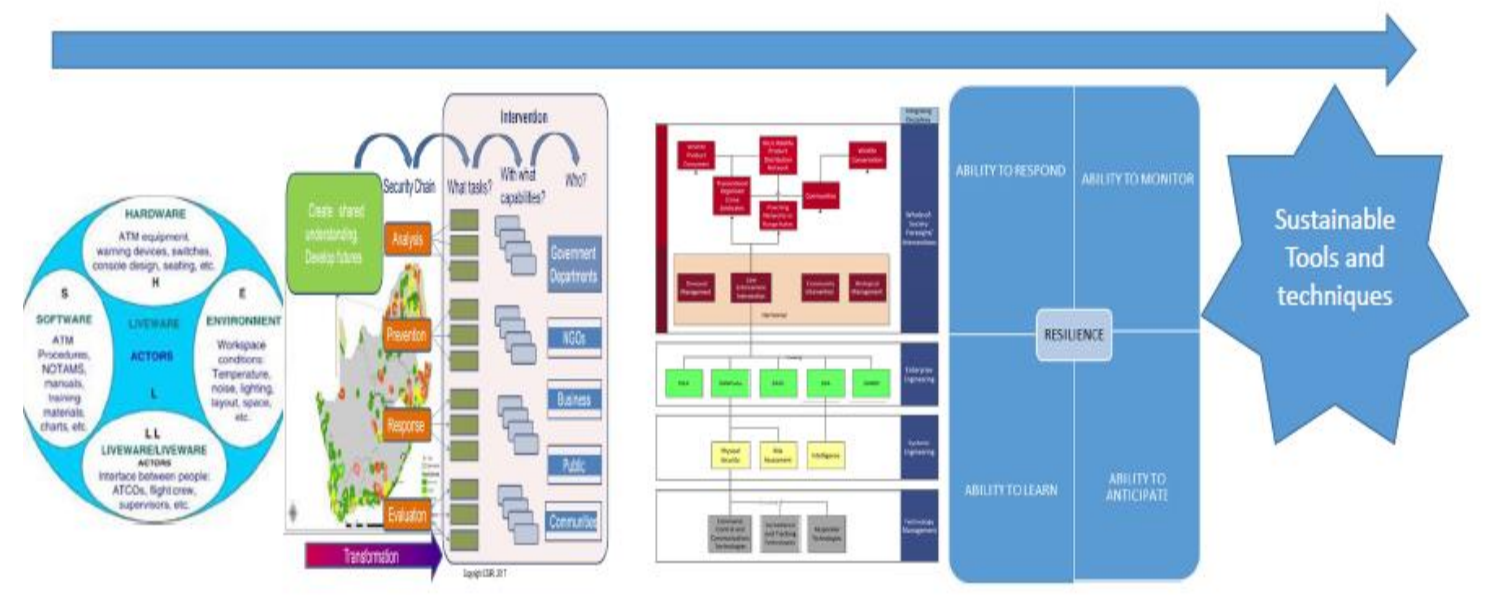

Figure 11: Conceptual framework flow to ensure sustainable resilient ATM systems for South Africa, drawing elements from other research [9], [12], [18], as applied here

Figure 11, from left to right, uses figures from models to give a visual representation of the items to consider when gathering data and completing analysis to arrive at sustainable tools and techniques. It is a 'check and balance' to assist the researchers through the steps. For more detailed images, refer to [9], [12], and [18].

\section{TESTING THE FRAMEWORK FOR VALIDITY AND RELIABILITY}

The development of this initial conceptual framework for ATM resilience and sustainability was exploratory. Its foundation is in complexity theory, and it combined different theories or models to be able to analyse an entire air traffic control system's management in a specific location through a qualitative examination. The framework shows that there is a strong possibility for a more durable system by combing science and theories. The framework requires further development, and it is proposed that this be done via a fourstage continuous improvement cycle. It is proposed that the data throughout the research be analysed by technical qualitative phenomenology procedures to acquire tools and techniques to ensure sustainable and resilient ATM systems for South Africa.

The first stage of the research will involve the model used in the SMS of SHELL. This will be used to gather the components' interactions through a review of all policies, procedures, and operating manuals.

The second phase would employ the whole-of-society theory concepts outlined in Goncalves' article, 'Complexity and the integrating disciplines' [12]. It would use the data obtained from the first stage to develop semi-structured interviews.

The third stage is validation using the RAG. This grid, which focuses on responding, monitoring, learning, and anticipating, will also be used with semi-structured interviews after the analysis of the interviews has been completed in the whole-of-society stage.

The fourth stage will identify possible sustainable tools and techniques for resilience in ATM. These tools could be training scenarios, more robust instructions and procedures, or different equipment. They cannot be properly identified or suggested without the first three stages. The tools and techniques will need validation through training and repeating of some of the stages in both short- and long-term applications.

\section{CONCLUSION}

A conceptual framework that is supported by complexity science through the integration of the disciplines from an SMS SHELL model and whole-of-society approach needs to be developed. This would lead to tools and techniques, validated through triangulation and employing the RAG [10] to demonstrate resilient performance. This would take the current ATM system, which is based on safety management, to a higher functioning system that mitigates or possibly prevents adverse events [10]. 
Multiple models need to be employed to ensure that ATM is sustainable and resilient because it is a complex system of systems that involves both safety and security. Also, each ANSP has specific visions and missions and essential air navigation services, and is dependent on the company, region, or country. However, they join with other ANSPs [19], so global harmonisation is possible.

This paper outlines the complex multi-disciplinary socio-technical system that directly supports the air transportation industry in any country and in South Africa in particular, with the need for several synchronised interventions to remain resilient. It is argued that the system will continue to need both safety and security analysis with validation for resilience. This may be done on the foundation of complexity theory, which will employ the SHELL and whole-of-society models to assess the current situations, followed by validation using RAG. This approach will identify the tools and techniques that are useful, because they are expected to contribute to the body of knowledge on safe, secure, and resilient airspace, for continuous improvement.

This paper concludes that complexity requires guidance at multiple levels in addressing complexity, in combination with security and safety for short- and long-term visions. It also agrees that further case studies are needed that employ deep transformation through whole-of-society, as deduced from technology administration, systems engineering, and enterprising engineering [12]. Goncalves' approach [12] to a new discipline in whole-of-society was discussed as being appropriate, and that the integrating effects are noteworthy for a new competence and disciplined approach to security. However, it may have limitations if safety is involved with security, as in the air traffic industry. Goncalves' approach [12] integrates governance and philosophy as a core with other disciplines, including many social and natural sciences. However, it is proposed that, owing to its additional complexity, integrating those concepts with the SHELL and RAG models is needed to build sustainability and resilience in ATM. Further research founded on complexity theory, employing all the models discussed here through a single site case analysis, could ensure that South Africa's ANSP leads the way in sustainability for a global harmonisation in ATM.

\section{REFERENCES}

[1] Zemrowski, K. 2008. Impacts of increasing reliance on automation in air traffic control systems, 2008 2nd Annual IEEE Systems Conference, Montreal, Que., 2008, pp. 1-6, doi: 10.1109/SYSTEMS.2008.4518987.

[2] Strohmeier, M., Schafer, M., Pinheiro, R., Lenders, V. \& Martinovic, I. 2016. On perception and reality in wireless air traffic communications security. In IEEE Transactions on Intelligent Transportation Systems, vol. 18, no. 6, pp. 1338-1357, June 2017doi:10.1109/TITS.2016.2612584.

[3] Weiland, L. \& Wei, G. 2018. Evaluating the impact of NextGen's air traffic system on aviaiton security. MATEC Web of Conferences, 2018, 189, 10030. doi: 10.1051/matecconf/201818910030.

[4] Abbott, R. 2020. Can resilience engineering and deep learning neural networks anticipate disruptions in the NAS? The Journal of Air Traffic Control, Spring 2020, pp. 15-22.

[5] Air Traffic Navigation Services (ATNS). 2019. Air traffic and navigation services SOC Limited integrated report 2019. Bruma: ATNS.

[6] Baxter, G. \& Sommerville, I. 2011. Sociotechnical systems: From design methods to systems engineering. Interacting with Computers, 23, pp. 4-17.

[7] Amalberti, R. 2001. The paradoxes of almost totally safe transportation systems. Safety Science, 37(2-3), pp. 109126.

[8] Francis, R. \& Bekera, B. 2014. A metric and frameworks for resilience analysis of engineered and infrastructure systems. Reliability Engineering \& System Safety. 121(Jan), pp. 90-103. doi.org/10.1016/j.ress.2013.07.004.

[9] Miller, M., Holley, S. Mrusek, B. \& Weiland, L. 2020. A change in the dark room: The effects of human factors and cognitive loading issues for NextGen TRACON air traffic controllers. Advanced in Neuroegonomics and Cogntive EngineeringApplied Human Factors and Ergonomics2019 Advances in Intelligent Systems and Computing, vol 953,. doi:10.1007/978-3-030-20473-0_16.

[10] Hollnagel, E. 2015. RAG - Resilience analysis grid. A technical note.

[11] Cook, A., Blom, H., Lilli, F., Mantegna, R., Micciche, S., Rivas, D., Vazquez, R. \& Zanin, M. 2015. Journal of Air Transportation Management, 42(Jan 2015), pp. 149- 158. doi:doi.org/10.1016/j.jairtraman.2014.09.011.

[12] Goncalves, D. 2017. Complexity and the integrating disciplines. INCOSE SA $13^{\text {th }}$ Conference 2017: Navigating an unsettled future, CSIR International Convention Centre, Pretoria SA.

[13] Goldreich, O. n.d. Introduction to complexity theory. Introduction to complexity theory. Lecture notes for a twosemester course [1999] Weizmann Institute of Science, Israel.

[14] Wood, H. \& Gidado, K. 2008. An overview of complexity theory and its application to the construction industry. N: Dainty, A (Ed) Procs 24 ${ }^{\text {th }}$ Annual ARCOM Conference, 1-3 September 2008, Cardiff, UK, Association of Researchers in Construction Management, 677-686..

[15] Ripley, R. \& Larkin, G. 2005. Applying complexity theory to aviation management. AIAA $5^{\text {th }}$ ATIO and $16^{\text {th }}$ LighterThan-Air Sys Tech. and balloon Systems Conferences Session ATIO 6: Aviaiton Economics and Management. AIAA2005-733. Published online doi:10.2514/6.2005-7331.

[16] Dekker, S., Cilliers, P. \& Hofmeyr, J. 2011. The complexity of failure: Implications of complexity theory for safety investigations. Safety Science, 49(6), pp. 939-945. doi.org/10.1016/j.ssci.2011.01.008. 
[17] Swilling, C. \& Peter, C. 2014. Linking complexity and sustainability theories: Implications for modeling sustainability transitions. Sustainability, 6(3), pp. 1594-1622. doi:10.3390/su6031594.

[18] Singh, S. 2012. Human factors: SHELL model.

[19] International Civil Aviation Organization. 2017. Document 9859 AN/474 Safety Management Manual (SMS), $4^{\text {th }}$ edition. Montreal.

[20] Miller, M., Holley, S., Mrusek, B. \& Weiland, L. 2020. Assessing cognitive processing and human factors challenges in NextGen air traffic control tower team operations. Applied Human Factors and Ergonomics,.

[21] Hawkins, F. 1987. Human factors in flight, $2^{\text {nd }}$ ed. Aldershot: Routledge.

[22] Goncalves, D. 2017. A whole-of-society approach to wildlife crime in South Africa. South African Crime Quarterly, 60, pp. 9-18.

[23] De Spegeleire, S. 2011. Ten trends in capability planning for defence and security. The RUSI Journal, 156(5), pp. 20-28. doi: 10.1080/03071847.2011.626270.

[24] Nicolescu, B. 2010. Methodology of transdisciplinarity - Levels of reality, logic of the included middle and complexity. Transdisciplinary Journal of Engineering and Science, 1(1), pp. 19-38.

[25] International Civil Aviation Organization. 2016. Document 4444: Procedures for air navigation services air traffic management, $16^{\text {th }}$ ed. Montreal Canada.

[26] Ricacardo, P., Di Gravia, G., Costantino, F., Falegnami, A. \& Bilotta, F. 2018. An analytic framework to assess organizational resilience. Safety and Health at Work, 9(2018), pp. 265-276. doi:10.1016/j.shaw.2017.10.005.

[27] Rodriguez, M., Lawson, E. \& Butler, D. 2019. A study of the resilience analysis grid method and its applicabilty to the water sector in England and Wales. Water and Environmental Journal 0 (2019) p.1-11. doi:10.1111/wej.12539.

[28] Goudge, S. 2019. Towards a resilient aviation cybersecurity. Cyber Security and Resilence Symposium, Aman Jordan, October 2019.

[29] Diessner, D., Wynsma, H., Riegle, L. \& Morrissey, P. 2019. Report to the AIA Civil Aviation Councel, Civil Aviation and Rugulatory and Safety Committee Civil Aviation Cybersecurity Industry Assessment and Recommendations. Aerospace Industries Association. Arlington VA. USA.

[30] International Civil Aviation Organization. 2017. Doc 10118 - Global aviation security plan, $1^{\text {st }}$ ed. Montréal: International Civil Aviation Organization.

[31] EUROCONTROL Airport CDM Team. 2017. The manual - Airport CDM implementation. $5^{\text {th }}$ ed. Brussels: EUROCONTROL.

[32] Wengraf, T. 2001. Qualitative research interviewing, $1^{\text {st }}$ ed. SAGE Publications.

[33] Richards, L. \& Morse, J. 2013. Read me first for a user's guide to qualitative methods, $3^{\text {rd }}$ ed. SAGE Publications. Thousand Oaks CA. USA. 